Okajimas Fol. anat. jap., 52 : 59-72, 1975

\title{
The Beginnings of Anatomy in Japan
}

\section{Teizo Ogawa}

The modern anatomical concept began in our country much later than in Europe. Usually we take the publication of "Kaitai-Shinsho" by Gempaku Sugita in 1774 as the starting point of the modernization of Japanese medicine. And as the appearance of Andreas Vesalius' "Corporis humani fabrica" in 1543 denotes the beginning of modern European medicine, it meant a delay of more than two centuries for Japan. In this respect, I wish to quote especially the opinion of Charles Singer, who in 1954 published the paper "How medicine became anatomical" in the British Medical Journal (Dec. 25). He mentioned in it, that even European medicine was not based on anatomy until the 16th century, when Vesalius and his contemporaries, Falloppio, Eustachio, and others attained great achievements in anatomy and changed the direction of the entire field of medicine.

I wish to begin my brief presentation of the medical history of Japan, by showing some interesting anatomical pictures contained in an old Japanese medical book. This book is "Ton-i-sho," written $1302-1304$ by Shozen Kajiwara (1266-1337), a priest-physician of the Kamakura period (Fig. 1). It consists of 50 volumes, one volume of which is devoted to anatomical pictures of the human viscera and bowels with explanations. And it is worthy of notice, that these pictures, though never accurate, are rather superior to the contemporary anatomical pictures of Europe.

The reason for this comparative superiority is clear. Their source was China, where late in the northern Sung dynasty in the 11.-12. century bodies of executed criminals were sometimes dissected, and the viscera were drawn for the benefit of medical studies. In the year 1113, a doctor named Yang Chiech (楊介) of Anhui province (安徽) compiled an anatomical book with the title "SonshinKwanchu-Zu", based on observations and drawings by those present at these authentic dissections done in mediaeval China.

These pictures with explanations were introduced to our country, and so appeared in the "Ton-i-sho" of Kajiwara. We have to keep in mind, that Prof. Needham, the famous British historian, has recently pointed out the relatively high standard of scientific and cultural studies in the northern Sung dynasty.

Almost at the same time when in Europe the epoch-making anatomical book "Corporis humani fabrica" of Vesalius appeared in 1543, the Portuguese reached our country, arriving at Tanegashima, south of Kyushu, opening for the first time direct contact between Japanese and European people. As a result firearms were introduced to our country. We should also remember, that the great work "De revolutionibus orbium coelestium" of Nicolaus Copernicus (14731543), the renowned Polish astronomer who was also a physician, was published in the same year. The year 1543 is therefore a very great year in the cultural progress of mankind, because of these two books: one by Copernicus on the 


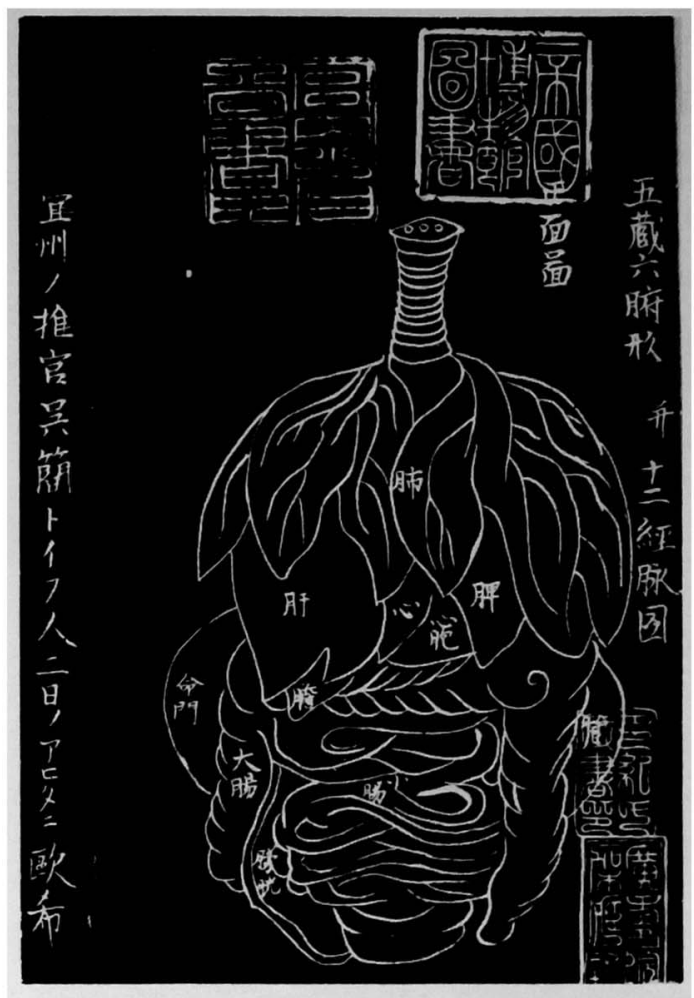

Fig. 1. One of the anatomical pictures in the medical book (13021304) by Shozen Kajiwara.

macrocosmos, the universe, and the other by Vesalius on the microcosmos, the human body.

Five years later, that is in 1549 , Francis Xavier, a Jesuit missionary, came to our country, and introduced Christianity. Some of the Jesuit priests practiced western medicine, especially surgery. From the medico-historical point of view, it is interesting for us to know how effective were the surgical treatments of the so-called "Southern Barbarians" in Japan and how much the Japanese could understand their methods and doctrines. In my opinion, the Jesuit priests were better able to teach the spirit and mercy of Christianity than anatomy and physiology. We have to bear in mind, that it corresponded exactly to the time, when Ambroise Pare (1510-1590) of France was revolutionizing surgery in
Europe, and was still before the discovery of blood circulation by William Harvey of England (De Motu cordis, 1628).

Chiefly because of fear of the propagation of Christianity, the Tokugawa government closed our country from the world in 1639 . Only a small number of Dutchmen and Chinese were permitted to stay in Nagasaki for the purpose of commerce. The Dutchmen were restricted to living in Dejima, a small, artificially constructed island, within the harbour of Nagasaki. During more than two centuries, Dejima remained as the sole small window, through which intercourse between Japan and the western world took place.

Some of the Japanese interpreters, living in Nagasaki, could learn European medicine, especially surgery, from Dutch doctors staying in Dejima, and some 


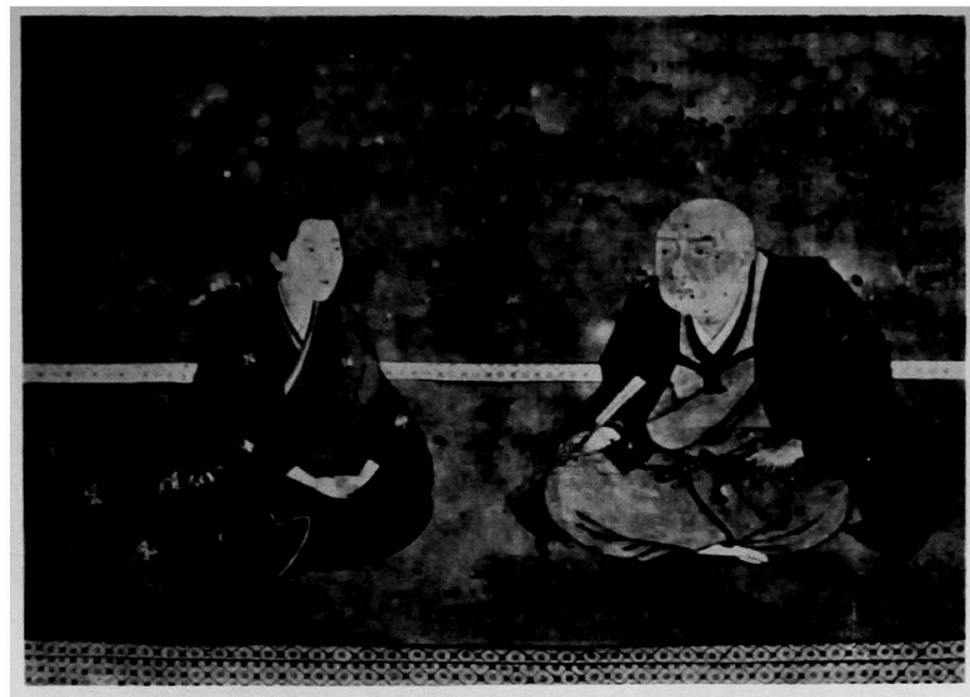

Fig. 2. Portraits of Ryoi Motoki and his wife.

Japanese physicians could get that knowledge at Nagasaki. It was called "Komo-geka" (Red hair surgery) or "Oranda-geka" (Holland surgery).

It is quite interesting, that Ryoi Motoki (1628-1697), one of the leading interpreters (Fig. 2), translated very early and very insufficiently an anatomical book originally written by Johann Remmelin (Pinax Microcosmographicus, Dutch edition, Amsterdam, 1667). This book was printed with the title "OrandaZenku-Naigai-Bungo- $Z u$ " in 1772 , that is, 75 years after Motoki's death. Recently we were able to verify that the translation of Motoki was accomplished not later than 1682 , nearly one century before the publication of "Kaitai-Shinsho".

About the same time that Motoki translated the above anatomical book, the trend towards empiricism began to gain power among Kampo physicians (Kampo means Japanized medicine of Chinese origin). They were called Koi-ho (古医方), meaning classical medicine, and its two leading figures were Gen-i Nagoya (1628-1696), and Konzan Goto

\section{(1659-1733).}

Toyo Yamawaki (170j-1762), a pupil of the latter, was suspicious of the reality of the $5-\mathrm{Zo}$ (viscera), 6-Fu (bowels)

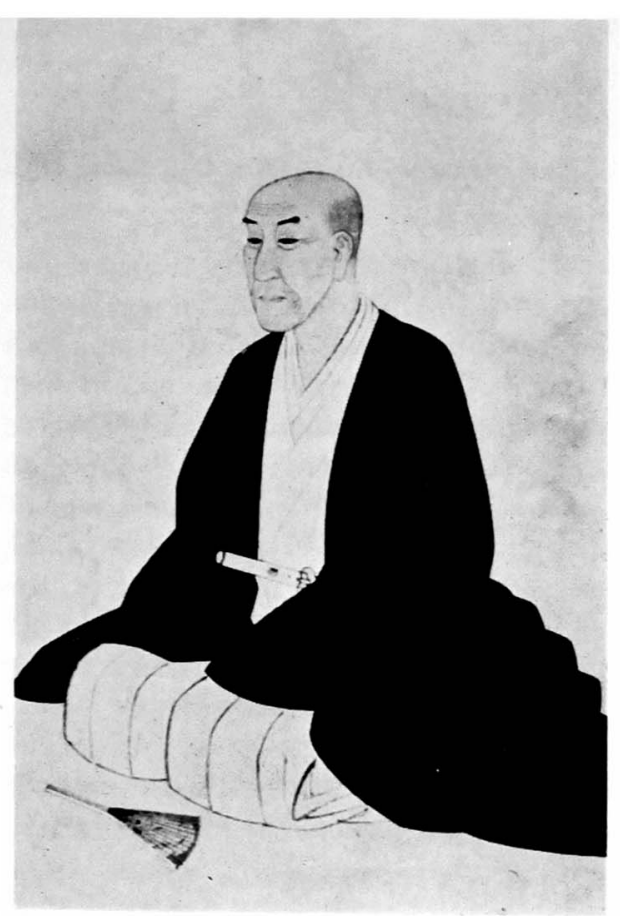

Fig. 3. Portrait of ToyogYamawaki. 


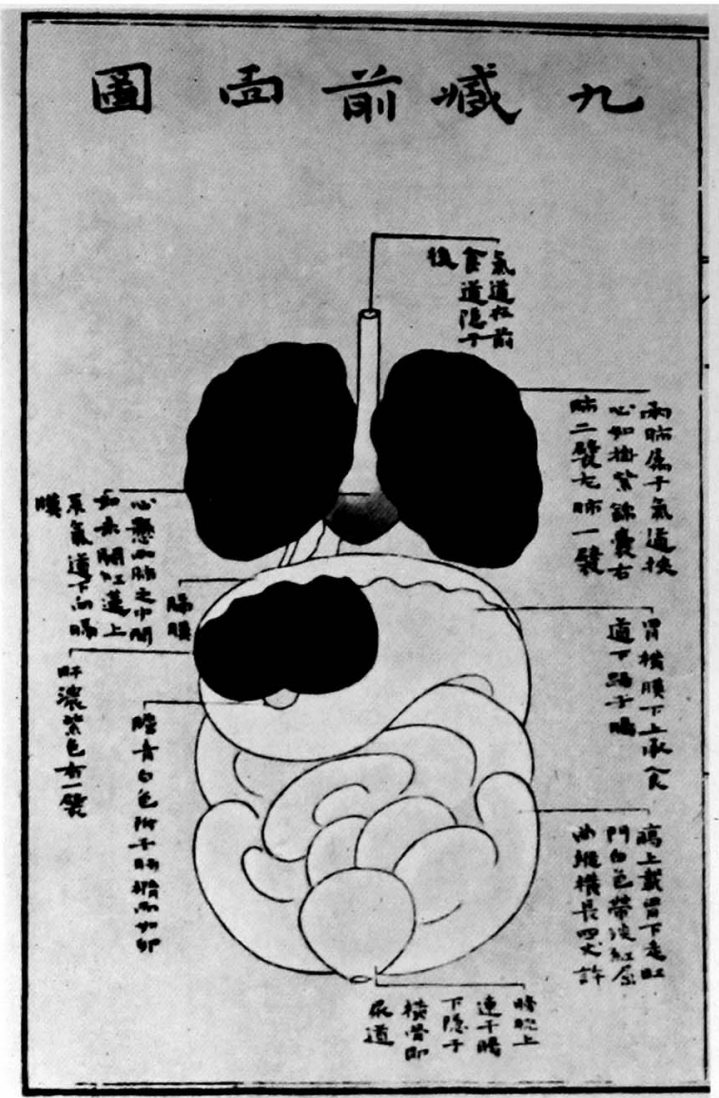

Fig. 4. An anatomical picture from the Zoshi.

theory of Chinese medicine (Fig. 3), and succeeded in 1754 to get official permission in Kyoto for dissection of a decapitated criminal. Yamawaki with other physicians attended the autopsy, and he wrote the book "Zoshi", meaning "Notes on Viscera", publishing it by wood-cut print five years later (1759). In this book he stressed strongly the importance of the empirical method in medicine indicating many errors of $5-\mathrm{Zo}, 6-\mathrm{Fu}$ theory of the classical Chinese medicine (Fig. 4). Moreover, he mentioned the correctness of the anatomical pictures in a European book he consulted, probably that of Johann Vesling (1598-1649).

Many objections were raised against Yamawaki's bold action. Some persons said that ${ }^{7}$ it was cruel, opposed to the teachings :of the thancient saints; others argued that it did nothing useful for curing patients. But defenders of Yamawaki also appeared one after the other in various places in Japan.

I wish to mention here the name of Toshuku Negoro, an ophthalmologist, who lived in or near Kyoto. His life history is unknown, but perhaps he belonged also to the Ko-i-ho school. He, himself, examined in 1732 the skeletons of two criminals condemned at the stake, and wrote in 1741 an article on all the bones and articulations with pictures and explanations (Fig. 5). In it he emphasized 


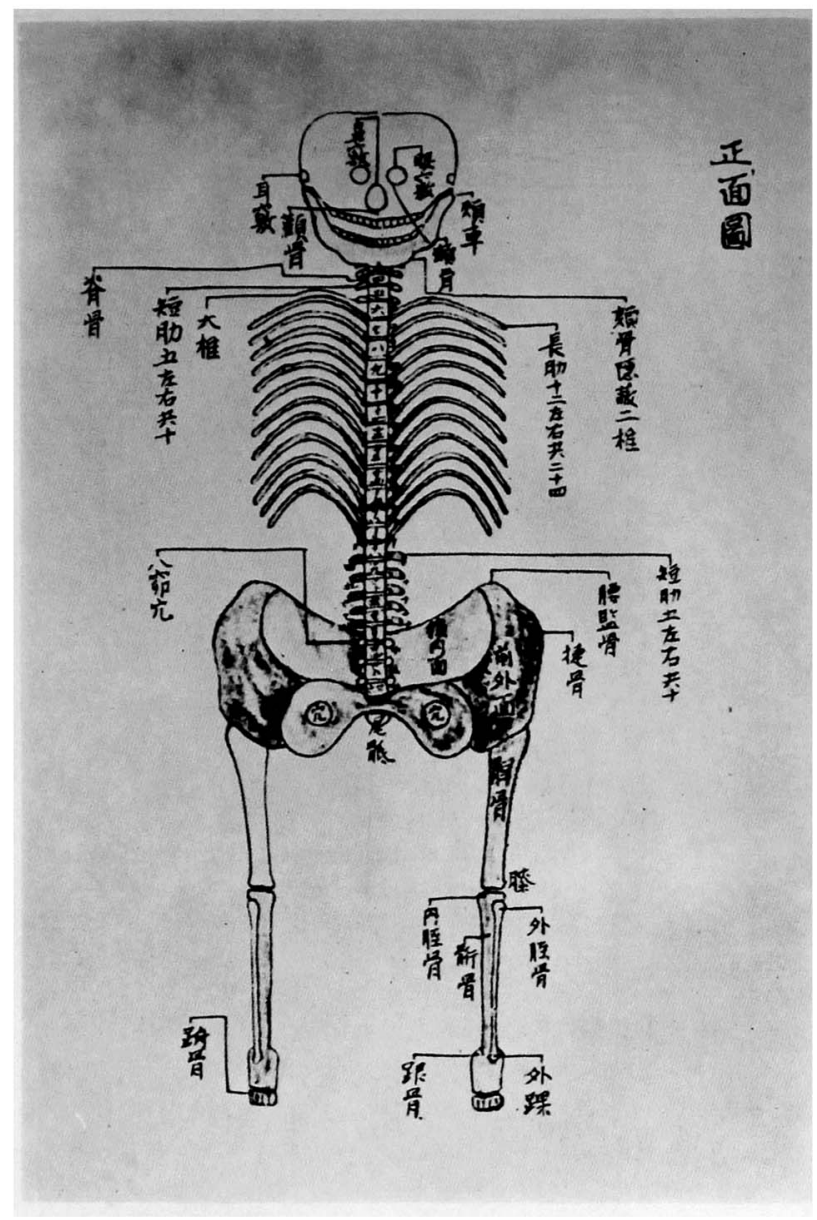

Fig. 5. Human skeleton drawn by Toshuku Negoro.

strongly the importance of real observation, rejecting the trend towards meditation in medical studies. Negoro's study of the human bones was not published, but his ardent work deserves to be cited as a forerunner to Yamawaki's autopsy.

In the spring of 1771 , the dissection of a female body after execution took place at Kotsugahara in Yedo (now called Tokyo), where Gempaku Sugita (17331817), Junnan Nakagawa (1739-1786), both belonging to the Obama clan, and Ryotaku Maeno (1723-1803) of the Nakatsu clan, were in attendance. Sugita and Maeno had each brought along the same Dutch anatomical book, " Ontleedkundige Tafelen" (1734, Amsterdam) originally written by Johann Adam Kulmus (Fig. 6). They were deeply impressed by the coincidence of their own observations of the interior of the human body with the anatomical pictures of this book.

The same day on their way home, the three, Maeno, Sugita, and Nakagawa promised to undertake by themselves the translation of Kulmus' book from Dutch into Japanese, and the next day they began the work at Maeno's house. Of the three only Maeno had some knowledge 


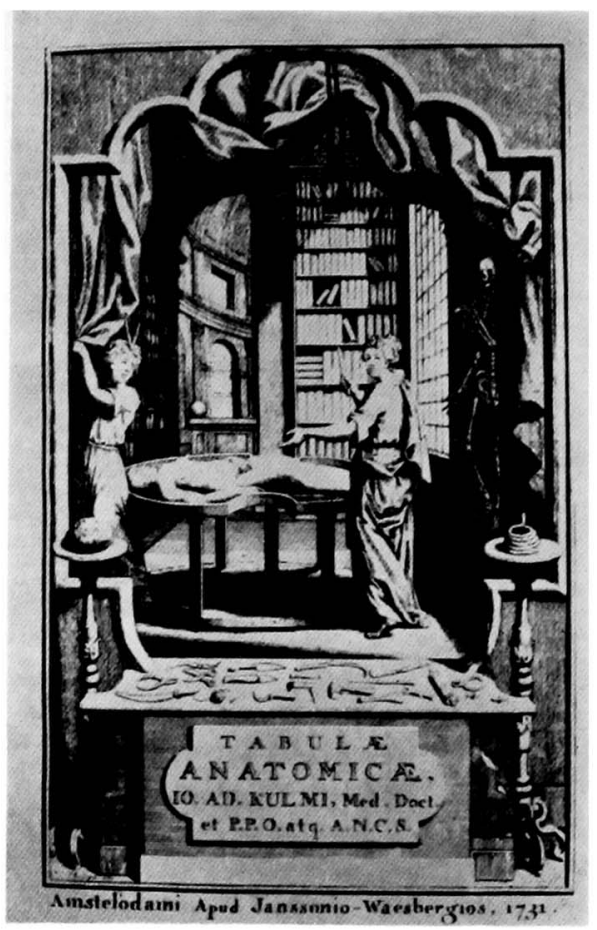

Fig. 6. The pictorial title-page of the Ontleedkundige Tafelen.

of the Dutch language, but it was too poor to read a Dutch book adequately.

In the strictly closed Japan, no one was permitted to learn western languages at first, except for interpreters in Nagasaki, but in about 1740 , the 8 th Shogun, Yoshimune Tokugawa (1684-1751), who had been well aware of the usefulness of Dutch books ordered unofficially two scholars living in Yedo to learn the Dutch language. One of the two was Kon-yo Aoki (1698-1769); from him Maeno had an opportunity to learn Dutch. After Aoki's death Maeno went to Nagasaki by order of Lord Okudaira of the Nakatsu clan, staying there about 100 days. He did his best to learn the Dutch language from interpreters, such as Yoshio, and Narabayashi.

In 1771 Maeno (Fig. 7) stood at the top in

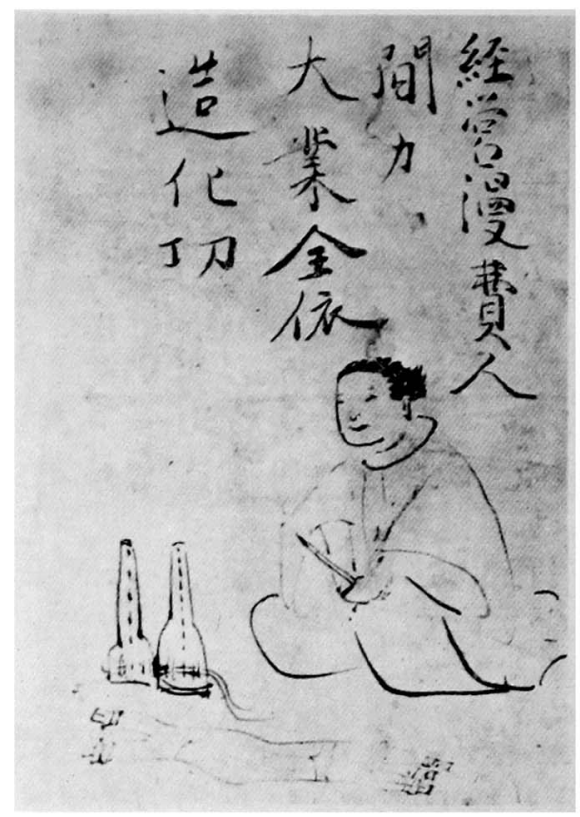

Fig. 7. Self-portrait of Ryotaku Maeno, with his self-composed maxim in Chinese characters.

reading Dutch among scholars in Yedo, and so became unanimously the leader of this translation group, as other members, Sugita, Nakagawa, and Hoshu Katsuragawa (1751-1809), who joined the group soon after the start of the work, had nearly no knowledge of the. Dutch language at that time. It is evident now, that Maeno wrote at first a small introductory book of the Dutch language ("Ranyakusen", May, 1771) for his colleagues. The translation was for them an awfully difficult task. But after 3 years and a half of very strenuous work they succeeded in translation to a certain degree, and the "Kaitai-Shinsho", meaning "New Book of Anatomy" was published in Yedo (1774), with the name of Gempaku Sugita as the person most responsible for this book (Fig. 8). It consisted of 5 volumes, one of which contains many anatomical pictures. 
Maeno's name is seen only in the preface written by Kogyu Yoshio, a leading interpreter in Nagasaki.

Sugito's ability to read Dutch stood far behind Maeno's, but Sugita (Fig.9) was the most fervent promoter of this work, and wrote, himself, the text translated by the group. He was certainly the writer and compiler of this "New Book of Anatomy".

It is to be noticed, that Kulmus' book has besides texts and pictures a large amount of footnotes, which are not so significant for beginners. Sugita, Maero, and their colleagues translated nearly all of the texts word for word, but left the footnotes untouched. The anatomical pictures printed by wood-engraving in the "Kaitai-Shinsho", contain nearly all of the pictures in Kulmus' book, but adding to them, some other pictures which were adopted from such anatomi-

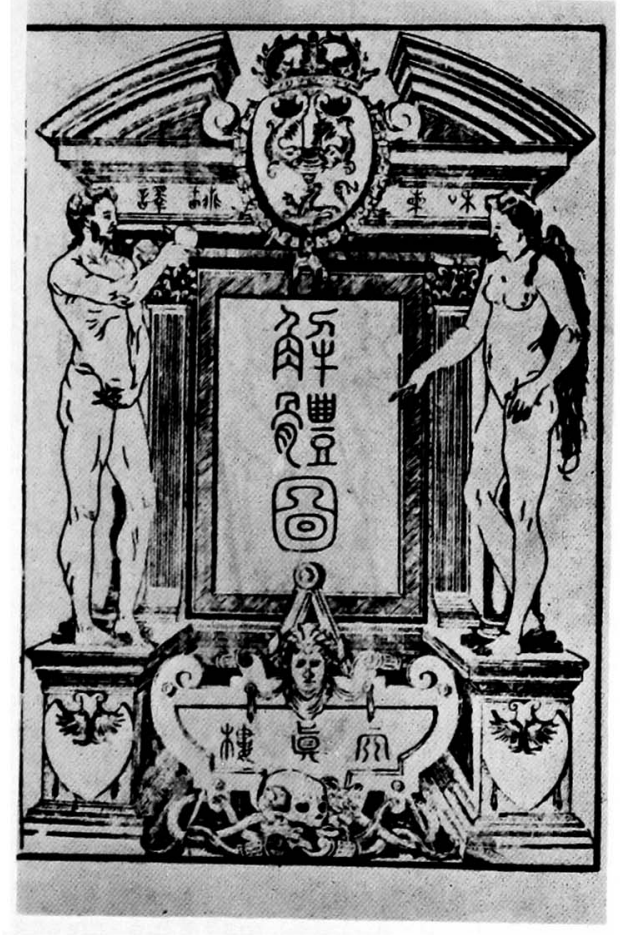

Fig. 8. The pictorial title-page of the Kaitai-Shinsho.

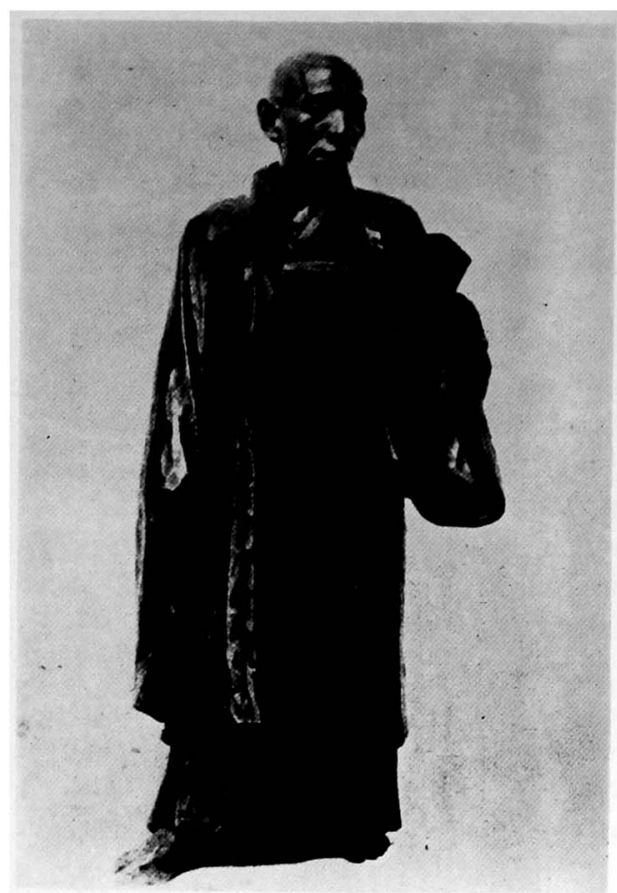

Fig. 9. Wooden statue of Gempaku Sugita.

cal books as those of Caspar and Thomas Bartholin, Steven Blankaart, Volcher Coiter, Govert Bidloo, etc.

The significance of the "Kaitai-Shinsho" for the medical world of Japan was very great. Existence of the nervous system, and the meaning of the brain and spinal cord were a surprise to Japanese physicians; the circulation of blood and lymphatic system, both of which had been quite recently discovered in Europe, were known to the Japanese.

With the "Kaitai-Shinsho", the time of "Rangaku”, meaning Dutch learning, began in our country, and showed gradual progress throughout the country. This demonstrated that Japanese people, aside from interpreters in Nagasaki could learn to read Dutch books, if they concentrated on it hard enough. Maeno and Sugita were highly respected as the founders of "Rangaku".

A number of young students came to 
them, or to the other collaborators of "Kaitai-Shinsho", to learn the Dutch language, and the "Rangaku" began to spread from Yedo to many districts of Japan.

In my opinion, it is very necessary to consider that the time was ripe to accept and estimate western anatomy, when the "Kaitai-Shinsho" appeared in our country (1774). The empirical method was just beginning to prevail in Japanese medicine, and a number of Japanese physicians and politicians were well aware of the superiority of western medicine.

I wish to mention here two great scholars of that time. They were Baien Miura (1723-1789), a famous philosopher, and Goryu Asada (1734-1799), a noted astronomer, both of whom belonged to the Kitsuki clan of Bungo province. They were both physicians, and the latter ran away unofficially from Kitsuki to Osaka, spending there the rest of his life in studying the macrocosmos (the universe) and the microcosmos (the human body) by his own observations. Miura lived most of his life at Tominaga village in Bungo, and wrote many outstanding books on natural philosophy. Miura and Asada were very intimate friends and many letters between them are still in existence. It is shown, that they both purposefully dissected various kinds of animals. Neither Miura, nor Asada belonged to the "Rangaku" school.

Asada's anatomy of the human body was compiled by Riken Nakai (1732-1817), his sympathizer and friend, and a famous Confucianist in Osaka, in the book "Essorohitsu" (1773), written one year before the "Kaitai-Shinsho". I estimate this book highly, because it shows probably the highest level of Japanese anatomy just before the "Kaitai-Shinsho".
As to the importation of western medicine into our country, the "IhanTeiko" of Genshin Utagawa (1769-1834) is especially worthy of notice. Utagawa was a prominent pupil of Maeno and Sugita. The "Ihan-Teiko", consisting of three volumes, was published in 1805 , and three years later, as its supplement, one volume of anatomical pictures, by copper-etching for the first time in Japan made by Zenkichi Nagata, was issued. The text of the "Ihan-Teiko" was very instructive and effective for Japanese people to understand the essence of western anatomy including, partially, physiology and pathology. We suppose this book might have been the most popular one among translated medical books until the end of the Tokugawa period.

Another very important book of anatomy was the "Chotei-Kaitai-Shinsho" of Gentaku Otsuki (1757-1827), which was published in 1826 (Fig. 10). "Chotei" means "revised". Otsuki, when young, studied the Dutch language under Maeno and Sugita and grew to become the greatest authority in "Rangaku". Through him the Dutch learning flourished in wide areas of Japan, as many students assembled to his private school called "Shirando" in Yedo. When Otsuki was still a youngster, he was asked or ordered by Sugita to revise the "KaitaiShinsho", because the latter himself knew well the insufficiency of their first and hasty translation of Kulmus' book.

Otsuki corrected many errors in translation made by his teachers and succeeded in preparing the manuscript of the "Chotei-Kaitai-Shinsho" in 1798. But its publication by printing was very much delayed till 1827, owing to various circumstances. It was published one year after the time when Philipp Franz von Siebold (1796-1866) made his famous inland trip (1826) between Nagasaki and 


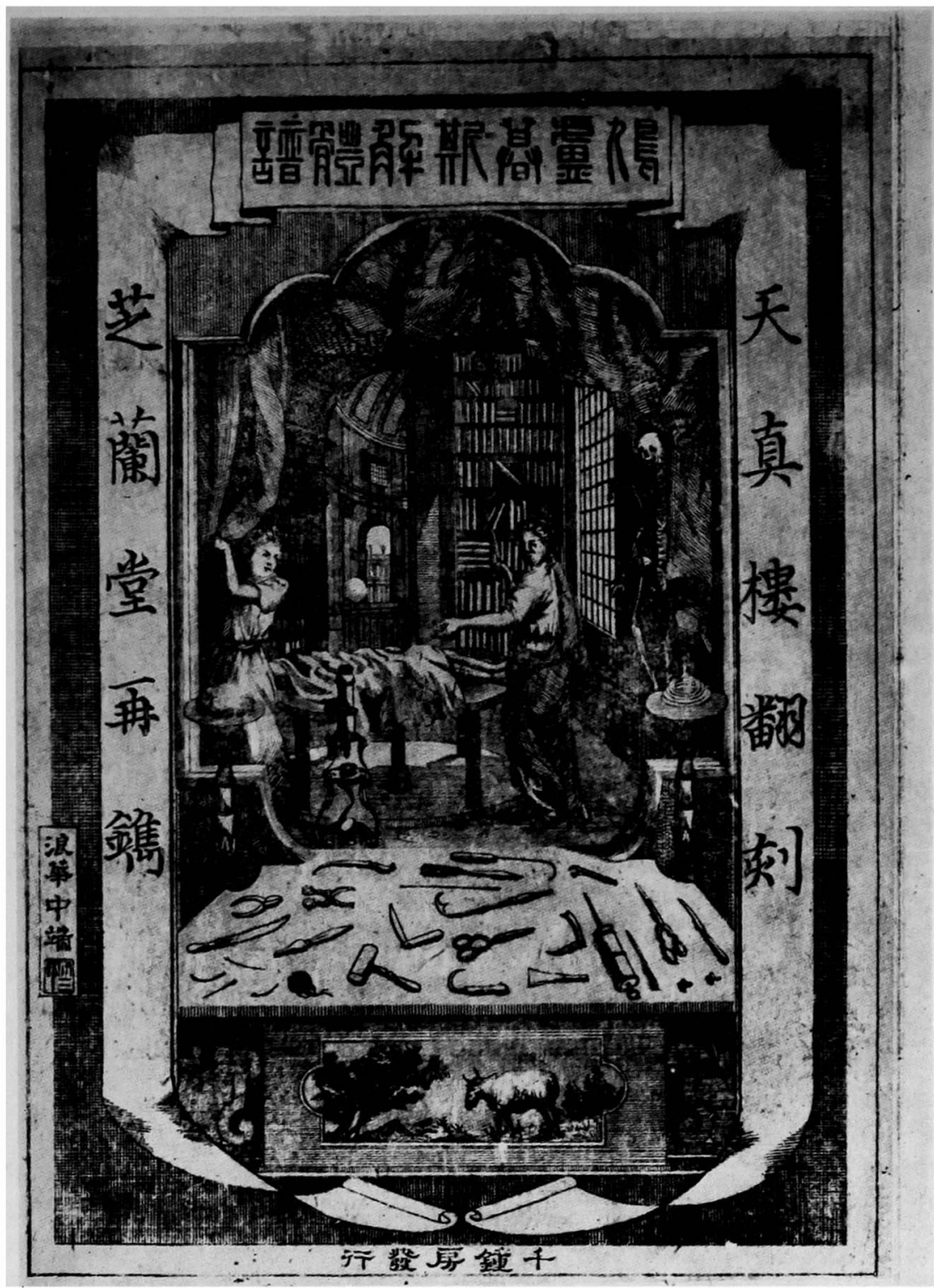

Fig. 10. The pictorial title-page of the Chotei-Kaitai-Shinsho.

Yedo.

The "Chotei-Kaitai-Shinsho" consists of 13 volumes and another volume showing anatomical pictures by copper-plates etched by Isaburo Naka. We might say that probably this is the most complete Japanese anatomical book produced during the Tokugawa period.
We have now in our country a large number of anatomical pictures drawn in the Tokugawa period. Most of them have the characteristic of having been prepared as "Kaibo-emaki", meaning scrolls of anatomical pictures. The most famous one is the Heijiro-Zozu. The dissection 
of a man, aged 40 named Heijiro, was performed at Fushimi, south of Kyoto, in 1784. It was presided over by Nankei Tachibana and the chief painter was Ranshu Yoshimura. Genshun Koishi (1743-1808), who was a Ko-i-ho physician, but after reading the "Kaitai-Shinsho", was very much interested in western anatomy, also attended the autopsy and wrote explanations, using many anatomical terms particular to the "Kaitai-Shinsho".

Other famous anatomical pictures, called "Seyakuin-kaidantai-Zozu", were made in 1798, again drawn by Ranshu Yoshimura. "Seyakuin" is the name of a physician, who presided at the dissection of a male body, age 34 . This time, also, Genshun Koishi wrote explanations, and Sokichi Hashimoto, who had learned the Dutch language from Gentaku Otsuki in Yedo, wrote the name of each organ in Dutch words.

If we compare the pictures of "Heijiro" and "Seyakuin", we can ascertain that there was much progress in accuracy of anatomical knowledge in Japan. It is more so, when we look at the series of anatomical pictures made (1819) by Neiichi Minagaki in Yedo. But to our regret, nearly all of the anatomical pictures during the Tokugawa period were made in the style of Japanese painting. The perspective and the shadowing of the western style were not sufficiently used.

Existence of the lymphatic system seems to have aroused special interest among Japanese physicians. At the dissection of a male body at Kyoto in 1812 , that took place under the auspices of Fuzan Fujibayashi and Tou Komori, they stated with emphasis, that they could certainly find the thoracic duct for the first time in Japan. But the thoracic duct shown in the scroll does not prove this, as it is drawn so much akin to the corresponding picture in the "KaitaiShinsho".

Nine years later, at the dissection of a male body performed at Kyoto in 1821, the thoracic duct was really observed, the unamimous proof of which is seen in the book "Kaizo-Zufu" written and published in 1822 by Tozo Ikeda (Fig. 11). The participant, who took charge of that body portion was Gishin Komori, the 19 year old son of Tou Komori, who was the superintendent in charge of this dissection.

Nanryu Kagawa, a famous obstetrician in Osaka, wrote that he had in several female bodies studied the internal genital organs by dissection, and claimed some original findings concerning the relation between uterus and vagina, and the existence of the isthmus of the uterine cavity.

But notwithstanding the frequency of dissections of the human body in the late Tokugawa period, originality was nearly always lacking in anatomical observations in Japan at that time. They endeavoured only to confirm the well developed anatomy of the western countries.

One of the causes why originality was rare in that period, is that the cadavers were not allowed to be conveyed to a place fitted for detailed anatomical study, and moreover they had to finish the work nearly always within one day, by sunset. Sometimes more than one hundred persons assembled at the dissection of one human body, each group having to do an allotted task, and could not naturally study in detail and with precision.

Among them, I wish to mention especially the names of two Japanese orthopedists, Ryoetsu Hoshino of Hiroshima and Bunken Kagami of Osaka. To teach their pupils, they prepared very elaborate models of the whole human skeleton by wood carving. Hoshino's work was 


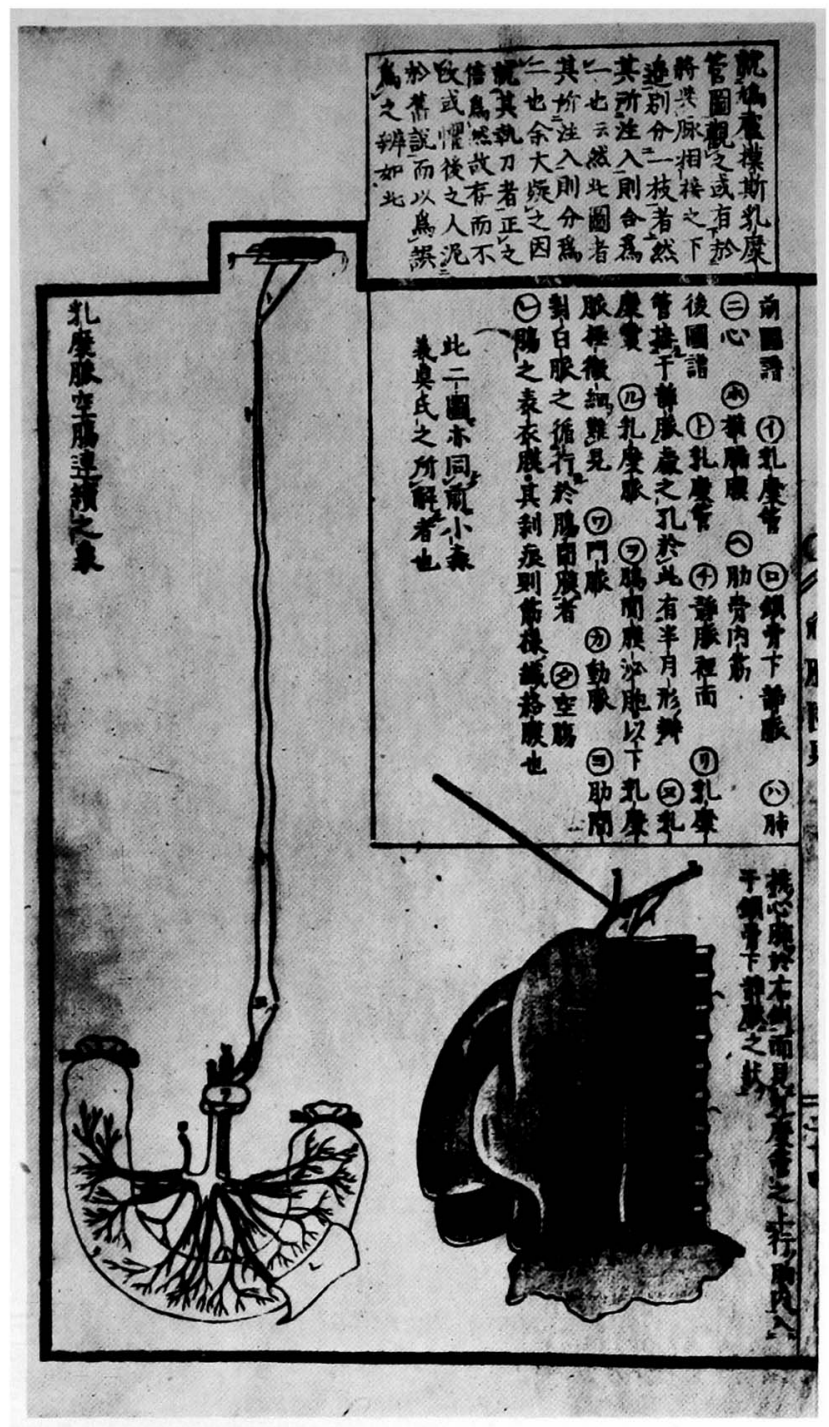

Fig. 11. The thoracic duct from the Kaizo-Zufu (1822).

chronologically prior to Kagami's. At present the wooden skeleton of the latter is preserved in the University of Tokyo, and one may be surprised by the accuracy of the model (Fig. 12).

Moreover, Kagami's orthopedic book "Seikotsu-Shinsho" consisting of 3 volumes, was published in 1810 . As an appendix to this book, he published one volume entitled "Kakukotsu-Shikei-Zu", meaning "True figures of each bone", which shows a relatively high standard of osteology. Such a production of wooden bones can be understood, as preservation of true bones was officially prohibited even for teachers of medicine and surgery.

With the fall of the Tokugawa government (1867), the new government of Emperor Meiji arose. Japan was opened, 


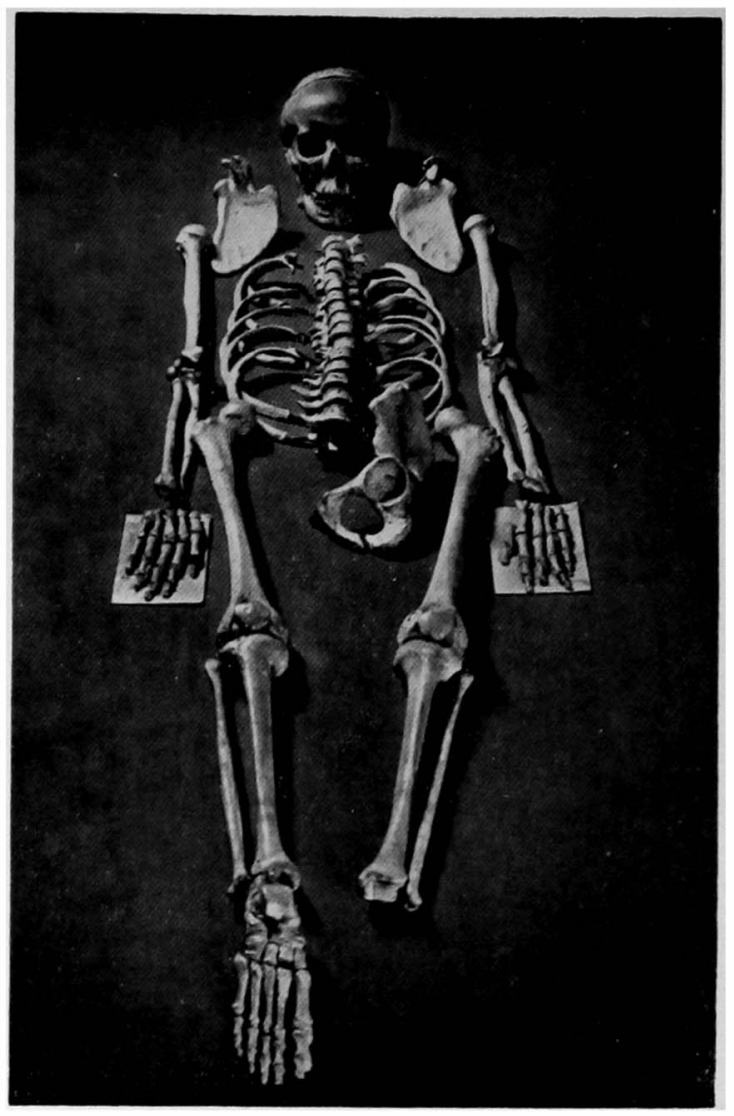

Fig. 12. Wooden skeleton of Kagami, now preserved in the University of Tokyo.

and they tried ardently to take in the western culture. Quite a new epoch started in our country. Soon after the resurrection occured a remarkable event, that of the autopsy of a woman, named Miki, aged 34 years, was performed, according to her own will before death by illness, at the Medical School in Tokyo in 1869. Following this, the government began to send many bodies of those executed or those who died by illness in prisons to the Medical School, for dissection for use in medical education. In the beginning of the Meiji era, Kazuyoshi Taguchi, who later became Professor of Anatomy in the University of Tokyo, worked most diligently at these dissections.
In 1871 two German professors, Leopold Müller and Theodor Hoffmann, came to Tokyo, by official invitation of the Japanese government. They established in Tokyo the German type system of medical education. Though Müller was a surgeon and Hoffmann an internist, they had to teach at first anatomy to Japanese students. Two years later, that is, in 1873, the anatomist Wilhelm Doenitz came to Tokyo, and began to establish an institute of anatomy, the first one in Japan.

As the successor to Doenitz, Hans Gierke reached Toky.o in 1877, and with him histology in Japan began. The arrival of Joseph Disse as the successor to Gierke was in 1880 . 
In the same year, Yoshikiyo Koganei graduated from the University of Tokyo School of Medicine, with prominent credits. Soon he was sent by the government to Germany to study anatomy. He was a very diligent and beloved pupil of Wilhelm Waldeyer at Strassburg and Berlin. He stayed in Europe more than four years, studying human anatomy, histology, embryology, and comparative anatomy, and published articles on the structure of the retina and iris.
Koganei returned home in 1885 , and began on the 11. Sept. of that year to give lectures in anatomy to Japanese students, as the successor to Disse. The next year he was appointed ordinary professor of anatomy at the Imperial University in Tokyo. From that time till today, a time span of 90 years, anatomical studies have gradually and steadily progressed, reaching very nearly the highest level of the world.

(Prof. emeritus of Anatomy, the University of Tokyo; Prof. of Medical History, the Juntendo University, Tokyo) 